\title{
A Study of Factors Influencing VCT Service Utilization among the Youths: A Case Study of Kapsabet Division, Nandi County, Kenya
}

\author{
Taratisio Ndwiga, Masta Omwono \\ Department of Environmental Health, School of Public Health, Moi Univeristy, Eldoret, Kenya \\ Email: taratisiondwiga@yahoo.com
}

Received 13 June 2014; revised 10 July 2014; accepted 3 August 2014

Copyright (C) 2014 by authors and Scientific Research Publishing Inc.

This work is licensed under the Creative Commons Attribution International License (CC BY). http://creativecommons.org/licenses/by/4.0/

(c) (i) Open Access

\begin{abstract}
Voluntary Counseling and Testing (VCT) is important in controlling the spread of HIV/AIDS especially among the Youths. The aim of the study was to determine the extent, to assess the level of awareness and to describe the Youths' attitude towards VCT Service Utilization in Kapsabet Division, Nandi Central District from $1^{\text {st }}$ February to $30^{\text {th }}$ April 2013. A cross-sectional descriptive study was carried out among male and female Youths aged 18 - 34 years who were selected by convenience sampling, using Quantitative and Qualitative methods of data collection with mean age of 26 years. The study found that $52 \%$ of Youths had visited VCT and the majority was aware about VCT through print media, TV/radio and IEC materials. Forth-six percent (46\%) said Post-Counseling was poor. Seventy seven $(77 \%)$ highlighted various challenges i.e. most VCT centers were openly located within the hospital and user fee Ksh. 20 was charged. The study also found that there was high level of awareness but slightly low utilization of VCT Services with only $52 \%$ having tested. Posters in VCT rooms were stigmatizing and this could have influenced their low utilization of VCT Services. Therefore there is need for dialogue with policy-makers, Youths and Stakeholders in regards to changing strategy for future efforts to increase the uptake of services among the Youths.
\end{abstract}

\section{Keywords}

Voluntary Testing and Counseling, Discrimination, Stigma, Youth, Service Providers

\section{Introduction}

Counseling in HIV and AIDS has become a core element in a holistic model of health care, in which psycholog-

How to cite this paper: Ndwiga, T. and Omwono, M. (2014) A Study of Factors Influencing VCT Service Utilization among the Youths: A Case Study of Kapsabet Division, Nandi County, Kenya. World Journal of AIDS, 4, 281-286. 
ical issues are recognised as integral to patient management. In Kenya, Voluntary HIV Counseling and Testing (VCT) is the process whereby an individual or a couple undergoes counseling to enable him/her/them to make an informed choice about being tested for HIV [1].

HIV and AIDS counseling has two general aims: 1) the prevention of HIV transmission; and 2) the support of those affected directly and indirectly by HIV. It is vital that HIV counseling should have these dual aims because the spread of HIV can be prevented by changes in behavior [2].

The VCT has three five major aims, such as working with an individual so that he or she understands the risks; helping to identify the meanings of high risk behavior; helping to define the true potential for behaviour change; working with the individual to achieve and sustain behaviour change.

Young people aged between 15 - 24 years account for more than 50 percent of all HIV infections worldwide. More than 6800 young people are newly infected with HIV and 5700 die each day throughout the world [3].

Young people are especially vulnerable to HIV infection due to early sexual debut, emotional and developmental factors, low condom use, biological and social vulnerabilities, sexually transmitted infections, poor healthseeking behavior, and alcohol and substance abuse. Sub-Saharan Africa remains the most affected region in the world with an estimate of 22.5 million people living with HIV. Approximately 1.7 million new infections occurred in sub-Saharan Africa in the year 2007 [4].

In Kenya, the number of people who have been tested for HIV has increased from 1000 in the year 2000 to more than two million in 2007. This has been partly attributed to an increase in number of counseling and testing sites from 3 in the year 2000 to close to 1000 in 2007 [1]. Most VCT clients have certain shortcomings i.e. transport difficulties and fear of being sighted at the heath facility may limit the number of people being tested [5]. In addition, there are factors such as inadequate skilled service providers and inadequate resources which might hinder the utilization of VCT services among the youths [1].

The purpose of this study was to assess factors influencing VCT service utilization among the youths aged 18 34 years in Kapsabet Division of Nandi central District, Nandi County, Kenya from February to April 2013.

In Kapsabet Division of Nandi Central District, only 10 to 20 clients attend the VCT centre at the district hospital. The observers within the vicinity act as the referees and begin to speculate the reasons why a person is visiting such structures. This shows that there is still a gap in normalizing the HIV/AIDS function within the policy framework and existing health care systems. The factors influencing VCT service utilization among the youths aged 18 - 34 years in Kapsabet Division-Nandi Central District were met by the three specific objectives: By determining the extent of VCT service utilization among the youths; assessing the level of awareness on VCT services by the youths; and describing the youth's attitude towards VCT services.

\section{Study Methodology}

Descriptive-cross sectional on factors influencing VCT service utilization among youths aged 18 - 34 years in Kapsabet Division was the study design. The study population was youth respondents aged 18 - 34 years, whereby all the persons aged between 18 and 34 years were interviewed. The target population was 500 youths. The sample size of 50 youths was sampled of either sex using convenience sampling. Fisher et al. 1998 [6], was used to calculate the sample size.

Data was collected using a pre-tested questionnaire for validity and reliability. Only selected Youths were interviewed and secondary data obtained from the Youth Fund Centers. The qualitative and quantitative methods were both applied during the research period. Data was analyzed using SPSS version 12.

\section{Results and Discussion}

\subsection{Results}

The questionnaires administered were Fifty, with 21 respondents aged between 18 - 22 years, while 24 were between 23 - 28 years and 5 were between 29 - 34 years old (Figure 1). The female respondents were 64\% and $36 \%$ males (Figure 2) while $70 \%$ were single with 30\% being married (Figure 3). On religious affiliation $84 \%$ were Protestants while 16\% Muslims (Figure 4). On occupational status $72 \%$ of the respondents were self employed while $28 \%$ were in the formal employment (Figure 5). On the level of education $70 \%$ had secondary education with $16 \%$ primary and only $14 \%$ with the tertiary education (Figure 6 ), while $50 \%$ were located from periurban with $40 \%$ coming from urban and $10 \%$ from the rural areas (Figure 7 ). 


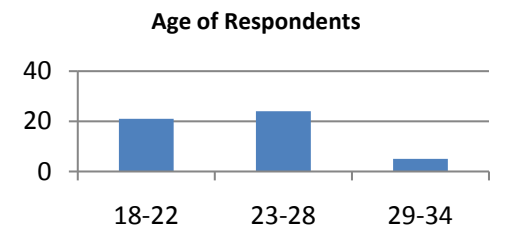

Figure 1. Age of respondents.

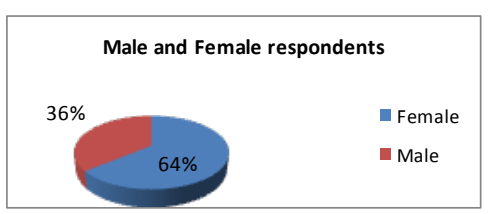

Figure 2. Male and female respondents.

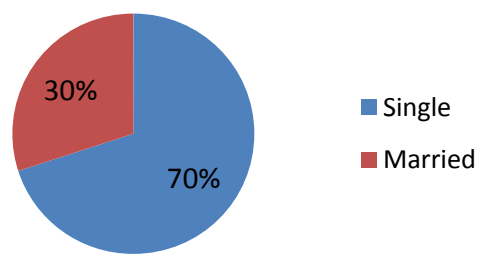

Figure 3. Marital status.

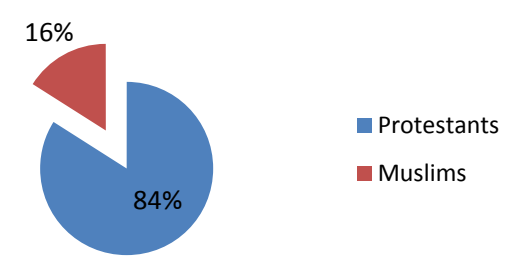

Figure 4. Religion N.

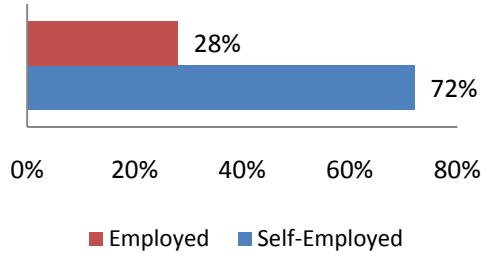

Figure 5. Respondents occupation.

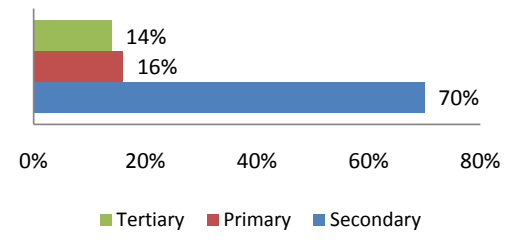

Figure 6. Level of education.

The majority (100\%) of the youth was aware about the VCT services and cited the sources of information as the print media, TV/Radio, VCT counselors, IEC materials and from the bill boards. It was found that 52\% had visited the VCT (Figure 8) while 48\% had not. On rating the VCT services, 58\% of the youth responded as not 
satisfactory, $23 \%$ good while $19 \%$ was fair (Figure 9). On the length of time taken $58 \%$ of the respondents took 3 hours, 23\% 2 hours while 19\% took 1 hour (Figure 10).

On the pre counseling services (Figure 11), 54\% of the respondents rated the services as good while $46 \%$ rated as bad. Of the $54 \%$ respondents took a short time as the queue was not long. On post counseling services $46 \%$ of the respondents rated the services as poor; with $35 \%$ good while $19 \%$ fair. On their comment about the VCT services (Figure 12), the youth responded that they required youth counselors, youth friendly sites, enough time to express their health problems, some posters on the counseling sites were stigmatizing and these might have influenced their attitude towards the VCT services.

On the challenges in accessing VCT services, $77 \%$ of the respondents highlighted that VCT sites were not privately located in the hospital and people will tell who enters the center. The charges Ksh. 20 by the Walter

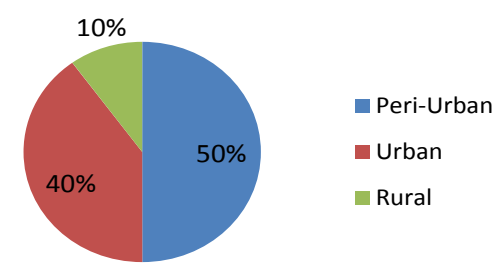

Figure 7. Location of the youth groups.

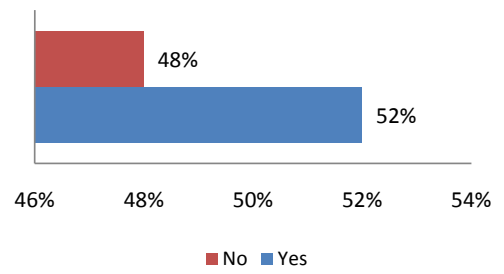

Figure 8. Whether they had visited VCT.

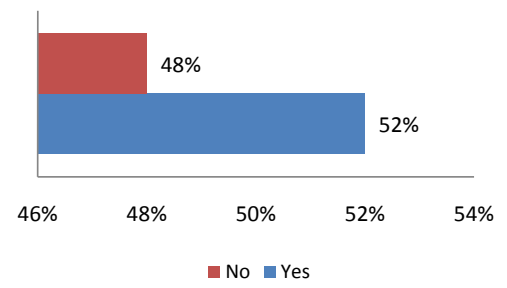

Figure 9. How they rated VCT services.

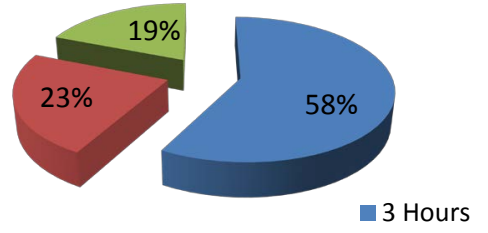

Figure 10. Length of time.

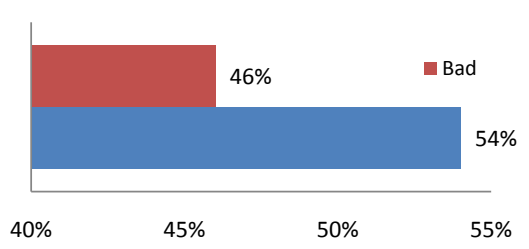

Figure 11. Pre-counseling services 


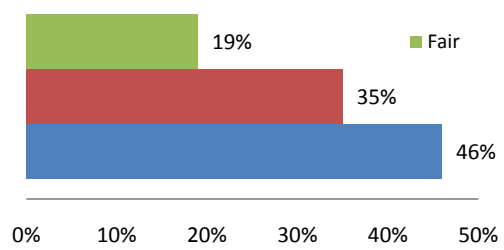

Figure 12. Post-counseling services.

Reed Foundation was too high for the unemployed youth. The respondent cited lack of privacy in the VCT centers as the youth and their parents might meet at the center.

\subsection{Discussion}

The study revealed that $52 \%$ had visited the VCT centre for various reasons. The major ones being desire to know their HIV status, getting married, planning for the future and because of getting into unprotected sex. These results are in agreement with [7] who stated that major reason for attending VCT was to sequel to having been ill VCT being part of ant-natal care screening. Most VCT services were located in Public health facilities.

The majority of youths obtained VCT information through the print media, TV/radio, IEC materials and the billboards. However there were more female respondents (64\%) than male (36\%). This result concurs with [8] research among adults which has shown that females utilize diagnostic services more than males.

The youth respondents cited general lack of confidence provided in public health facilities, fear of testing positive, stigmatization of the disease and death. In the absence of treatment option; many youth respondents does not see the benefits of testing, while testing itself regardless of the outcome was seen by many as putting one at risk of loss of social status and discrimination in the society.

Out of the $48 \%$ of the youth respondents, who had not been tested, had high level of stigma and negative attitude towards testing. The study found that testing was positively associated with education [6], available resources, knowledge that HIV causes AIDS, discussions with partners about HIV prevention and condom use at the last intercourse among those testing positive but negative associated with the number of sexual partners and living in rural areas.

Factor such as shortage of counselors, long queues, lack of privacy and lack of follow up support, following diagnosis and level of training and counselors influenced VCT service utilization among the youths in Kapsabet Division. This concurs with research done by [9]. This research paper determined the extent, level of awareness, and the youth's attitude towards VCT service utilization in Kapsabet Division Nandi Central District, Rift-Valley Province, Kenya.

\section{Conclusions}

This study demonstrated that there is a high level of awareness with the majority being aware of the VCT service through print media, TV/radio and from the bill boards. The study also found that $58 \%$ cited services as being not satisfactory and these could have influenced low utilization among the males as compared to the female youths.

The outcome of post counseling influenced the youth's attitude towards VCT. 46\% who rated post counseling as poor could have tested positive. Seventy-seven percent (77\%) cited various challenges in accessing VCT services i.e. centers were located in District Hospital and along open entrance, and most people could see the clients entering the VCT centre. Lack of privacy, youth counselors and payment of Ksh. 20 for counseling, and some posters in the VCT centers were stigmatizing and this could have influenced their attitudes towards low utilization of VCT services.

This study has shown that there is need to start a dialogue with various stake holders in providing VCT services to the youth, policy makers especially in regards to changing strategy of provision and disseminating information on VCT. The youths value anonymity and confidentiality which seem to lack in the regular Heath units and Hospitals.

\section{Recommendations}

The Ministry should either cut on cost or provide free test to the VCT clients and guarantee privacy and confi- 
dentiality to these people.

The center should provide a safe environment and convenient location.

They should have convenient working hours and offer outreach coverage and accessibility to the youths.

The posters at the VCT centers should be friendly and not scaring to the VCT clients.

\section{Acknowledgements}

We wish to thank PHO Kapsabet division for his tireless effort in assisting us during the research period.

\section{References}

[1] Mugo, M., Kibachio, C. and Njuguna, J. (2010) Utilization of Voluntary Counselling and Testing Services by women in a Kenyan village. Journal of Rural and Tropical Public Health, 9, 36-39.

[2] ABC of AIDS (2001) HIV Counseling and the Psychosocial Management of Patients with HIV or AIDS. BMJ, 322, 1533. http://dx.doi.org/10.1136/bmj.322.7301.1533

[3] (2013) www.ku.ac.ke/schools

[4] Dirar, A., Mengiste, B., Kedir, H. and Godana, W. (2013) Factors Contributing to Voluntary Counselling and Testing Uptake among Youth in Colleges of Harar, Ethiopia. Science Journal of Public Health, 1, 91-96. http://dx.doi.org/10.11648/j.sjph.20130102.17

[5] Nixon, S.A., Cameron, C., Hanass-Hancock, J., Simwaba, P., Solomon, P.E., Bond, V.A., Menon, A., Richardson, E., Stevens, M. and Zack, E. (2014) Perceptions of HIV-Related Health Services in Zambia for People with Disabilities Who Are HIV-Positive. Journal of the International AIDS Society, 17, 18806.

[6] Fisher, A.A., Laing, J.E. and Strocker, J.E. (1998) Handbook for Family Planning, Operation Research Design in Sampling. Population Council, 40-45.

[7] Amu, E.O., Ijadunola, K.T. and Odu, O.O. (2013) Assessment of Voluntary Counselling and Testing Uptake among Adults in Osun State Nigeria. Asian Medical Journal, 5, 48-54.

[8] Byamugisha, R., Tylleskär, T., Kagawa, M.N., Onyango, S., Karamagi, C.A.S. and Tumwine, J.K. (2010) Dramatic and Sustained Increase in HIV-Testing Rates among Antenatal Attendees in Eastern Uganda after a Policy Change from Voluntary Counselling and Testing to Routine Counselling and Testing for HIV: A Retrospective Analysis of Hospital Records, 2002-2009. BMC Health Services Research, 10, 290. http://dx.doi.org/10.1186/1472-6963-10-290

[9] Van Dyk, A.C. and Van Dyk, P.J. (2003) To Know or Not to Know: Service Related Barriers to Voluntary Counseling and Testing (VCT) in South Africa. Curationis, 26, 4-10. 
Scientific Research Publishing (SCIRP) is one of the largest Open Access journal publishers. It is currently publishing more than 200 open access, online, peer-reviewed journals covering a wide range of academic disciplines. SCIRP serves the worldwide academic communities and contributes to the progress and application of science with its publication.

Other selected journals from SCIRP are listed as below. Submit your manuscript to us via either submit@scirp.org or Online Submission Portal.
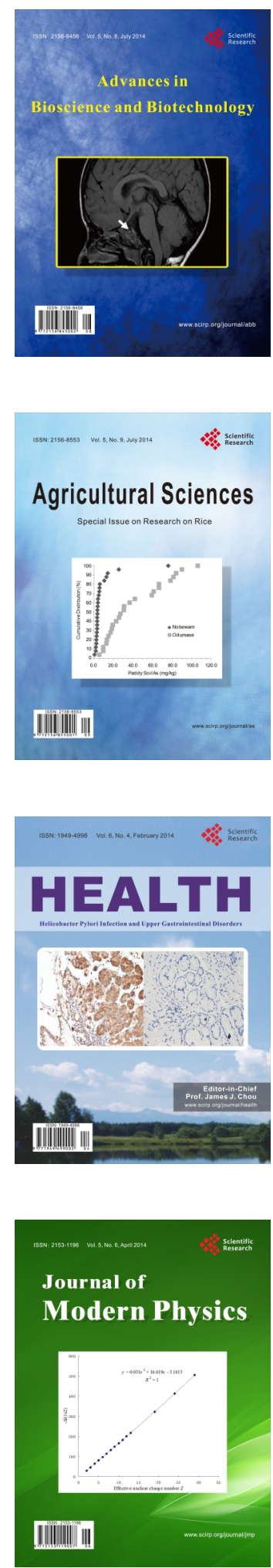
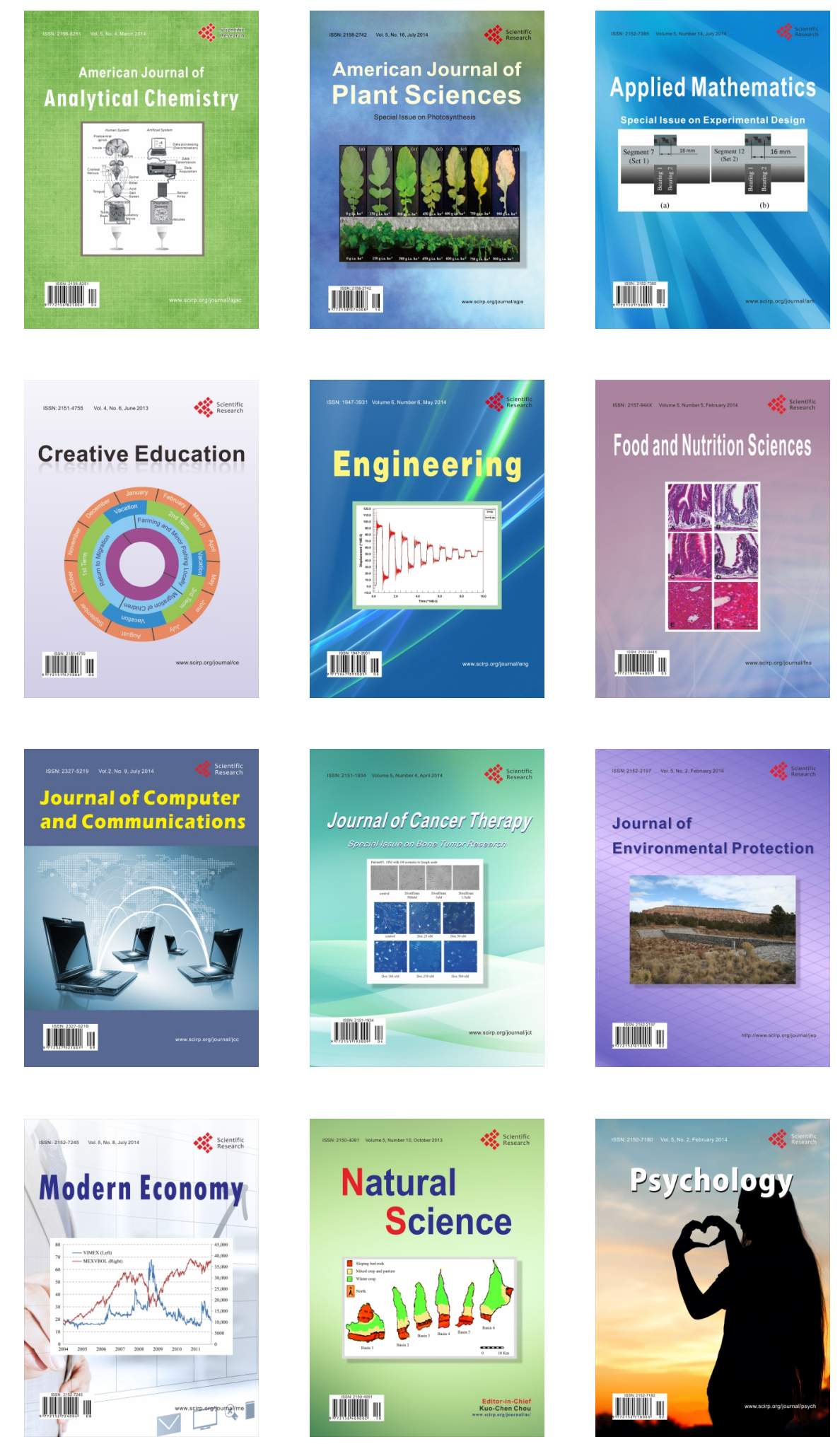